\title{
Optimum Process Parameters for Direct Metal Laser Sintering of Ti6Al Powder Blend
}

\author{
A. Zenani ${ }^{1}$, T. C. Dzogbe wu ${ }^{1, *}$, W. B. Du Preez ${ }^{2}$, I. Yadroitsev ${ }^{3}$ \\ ${ }^{1}$ Department of Mechanical and Mechatronics En gineering, Central University of Technology, Free State, Bloemfontein, South Africa \\ ${ }^{2}$ Centre for Rapid Prototyping and Manufacturing, Department of Mechanical and Mechatronics Engineering, Central University of \\ Technology, Free State, Bloemfontein, South Africa \\ ${ }^{3}$ Medical Product Development through Additive Manufacturing, Department of Mechanical and Mechatronics Engineering, Central \\ University of Technology, Free State, Bloemfontein, South Africa
}

Received February 19, 2020; Revised April 3, 2020; Accepted May 13, 2020

Copyright $\odot 2020$ by authors, all rights reserved. Authors agree that this article remains permanently open access under the terms of the Creative Commons Attribution License 4.0 International License

\begin{abstract}
Titanium aluminides have become the preferred titanium-based alloys for high temperature applications due to their resistance to oxidation at elevated temperatures. However, the inherent limitations of the conventional methods of manufacturing have adverse effects on the mechanical properties of the alloy and limit its applications. The current study focused on determining the optimum process parameters that could be used to produce a Ti6Al alloy with required microstructural properties and complex geometrical configurations using the direct metal laser sintering method. Single tracks were produced at laser powers of $150 \mathrm{~W}$ and $350 \mathrm{~W}$ over a wide range of scanning speeds. Continuous tracks were achieved only at a laser power of $150 \mathrm{~W}$ at corresponding scanning speeds of $1.0 \mathrm{~m} / \mathrm{s}$ to $1.4 \mathrm{~m} / \mathrm{s}$. A cross sectional analys is was conducted on the single tracks and $1.2 \mathrm{~m} / \mathrm{s}$ emerged as the optimum scanning speed. 3D objects were manufactured at optimu m process parameters of $150 \mathrm{~W}, 1.2 \mathrm{~m} / \mathrm{s}$ and a hatch distance of $80 \mu \mathrm{m}$. The microstructure of the $3 \mathrm{D}$ objects was homogenous which attests that the direct metal laser sintering method could be used to produce Ti6Al parts with the desired mechanical properties and geometrical complexity.
\end{abstract}

Keywords Process Parameter, DMLS, Powder Blend, Titanium Aluminide, Ti6Al, Single Tracks, Single Layers

\section{Introduction}

Titanium has been the preferred metal of choice for many engineering applications due to its outstanding specific strength, corrosion resistance and strength at high temperatures [1]. However, the structural integrity of titanium is limited by the increased oxidation of the alloy at temperatures above $600^{\circ} \mathrm{C}$ [2]. Titaniu $\mathrm{m}$ alu minide (TiAl) alloys have been proven to overcome the oxidation disadvantage which has provoked intense academic and industrial research into developing TiAl-based alloys for high temperature engineering applications. TiAl alloys can lead to substantial payoffs in a irc raft engines, industrial gas turbines and automotive parts due to their unique thermo mechanical properties. TiAl based alloys have a strong potential to increase the thrust-to-weight ratio in an aircraft engine [3]. These alloys could reduce the structural weight of high-performance gas turbine engines by 20 $30 \%$, which would enhance engine performance and fuel efficiency and potentially be a replacement of Ni-based superalloys that are nearly twice as dense (heavy) as TiAl-based alloys [4].

However, the conventional methods of manufacturing the alloy have limitations in the form of metallurgical defects, such as porosity, shrinkage and inhomogeneous microstructure which adversely affect the mechanical properties of the alloy [5]. Because of these limitations, manufacturing of TiAl components has focused on producing simple shapes and moderate dimensions only, to reduce the risks of metallurgical defects. However, the dynamics in the market have demonstrated that there is a high demand for large manufactured TiAl components for engineering applications at high temperatures [6]. To satisfy the industrial demand and the requirements of producing large TiAl parts with geometrical, technical and functional properties of complex shapes and homogenous microstructure, an alternative processing route(s) that satisfies the industrial requirements has to be exploited.

Direct metal laser sintering (DMLS), a subset of additive manufacturing (AM) which has received considerable attention due to its unique capabilities of manufacturing large co mp lex shapes, could be used to produced TiAlparts 
with structural integrity for high temperature applications. The DMLS manufacturing technology is recognised as a key technology in the Fourth industrial revolution, which can complement the inherent limitations of the conventional methods of manufacturing [7]. It is a monolithic manufacturing technology that manufactures 3D objects additively layer by layer which is diametrically opposed to the conventional subtractive manufacturing methods of manufacturing [8]. The technology can be used to manufacture $3 \mathrm{D}$ objects with complex geo metry and thin intricate walls, which is impossible to achieve using the conventional methods of manufacturing [9]. The manufacturing of titanium aluminide based components with specific geometrical and functional near net shape characteristics for high-temperature operations in gas turbines, aero-engines and automobiles would greatly reduce the time spent on manufacturing, reduce assembly and maintenance cost, avoid waste of manufacturing materials, improve performance reliability and weight reduction, hence the cost of manufacturing operations will be greatly reduced. The use of such intricate geometries would lead to fuelconsumption and e mission reduction and sustainable development at a lower cost [8].

It is already envisaged that the successful production of TiAl near net shapes would enable the production of aircraft engines with greater propulsion efficiency of a $20 \%$ reduction in fuel consumption, a $50 \%$ reduction in noise, and $80 \%$ reduction in NOx emissions compared to similar conventional engines [10]. Fro $m$ the above-mentioned, it is clear that there is a need for the development of TiAl components with near net shape for high value engineering applications at high temperatures. The study was aimed at determining optimum process parameters that could be used to manufacture Ti6Al alloy parts with complex geometry and homogenous microstructure for engineering applications at high temperatures.

\section{Materials and Methods}

The experiment was conducted using pure $\mathrm{Ti}(\mathrm{CP} \mathrm{Ti}$, grade 2) and $99.8 \%$ pure Al spherical gas atomized powders procured from TLS Technik GmbH. The powder was prepared for the in-situ alloying process by mixing 94 $\mathrm{wt} \% \mathrm{Ti}$ and $6 \mathrm{wt} \% \mathrm{Al}$. The Ti particle size was $<45 \mu \mathrm{m}$ and the Al powder particle size ranged from $20-45 \mu \mathrm{m}$.

An EOSINT M280 machine supplied by EOS GmbH was used for the experiment. The laser spot diameter of the mach ine is $\sim 80 \mu \mathrm{m}$. A Ti6Al4V substrate was used with a uniform powder deposition thickness of $60 \mu \mathrm{m}$. Single tracks were produced at laser powers of $150 \mathrm{~W}$ and $350 \mathrm{~W}$ over a wide range of scanning speeds $(\mathrm{V}=0.4-3.4 \mathrm{~m} / \mathrm{s})$. All tracks were of length $0.02 \mathrm{~m}$. For each scanning speed, three single tracks were produced.

The samples were mounted and metallurg ically prepared for optical microscopic analysis according to well-known procedures described in the literature [11, 12]. Cubes of dimension $10 \mathrm{~mm}$ x $10 \mathrm{~mm}$ x $10 \mathrm{~mm}$ (length $\mathrm{x}$ width $\mathrm{x}$ thickness) were produced for mic rostructural analysis. The samples were metallurgically prepared and etched with Kroll's reagent for examination. The distribution of Al in $\mathrm{Cp}$ Ti was determined in a scanning electron microscope (SEM) with an X-ray energy dispersive spectrometer (EDS). The surface roughness of the samples was measured with a Surftest SJ-210 portable surface roughness tester.

\section{Results and Discussions}

\subsection{Single Tracks}

Single tracks are the basic building units for additive manufacturing using the DMLS process. The geometrical characteristics of the single tracks have a decisive effect on the mechanical properties and surface morphology of DMLS built parts [9]. It is, therefore, obligatory to determine the optimum process parameters that could be used to produce continuous single tracks that would ultimately be used to produce the 3D object. The morphology of the solidified molten liquid (single tracks) produced in the current experiment that was conducted at laser powers of $150 \mathrm{~W}$ and $350 \mathrm{~W}$ with a wide range of scanning speeds is shown in Fig. 1.

From the top surface analysis, the single tracks were found to be continuous only at scanning speeds of $1.0 \mathrm{~m} / \mathrm{s}$, $1.2 \mathrm{~m} / \mathrm{s}$ and $1.4 \mathrm{~m} / \mathrm{s}$ at a laser power of $150 \mathrm{~W}$. The continuity or discontinuity (irregular or balling) of a track is determined by the hydrodynamic movement of the molten liquid which solidifies to form the tracks [13]. The melting process begins with a rapid rise of the surface temperature of the powder partic les resulting in the surface melting of the powder particles. The heat then flows to the core of the powder and melts the powder to form a molten pool. The characteristics of the molten pool are governed by the principal process parameters (laser power, spot size and scanning speed) and the powder layer thickness. These principal process parameters determine the laser energy input which influences the geometrical characteristics of the solidified single tracks [14]. A continuous track is formed when the is an optimal combination of the powder layer thickness, laser power and scanning speed. Discontinuous tracks are produced when the combination of the principal process parameters is not optimal [8]. The literature reveals that several authors attempted to explain the phenomenon behind the behaviour of the molten pool and the solidified single tracks. Several theoretical and experimental models have been proposed to predict the behaviour of the molten pool and its solidification mechanism $[13,15,16]$. 


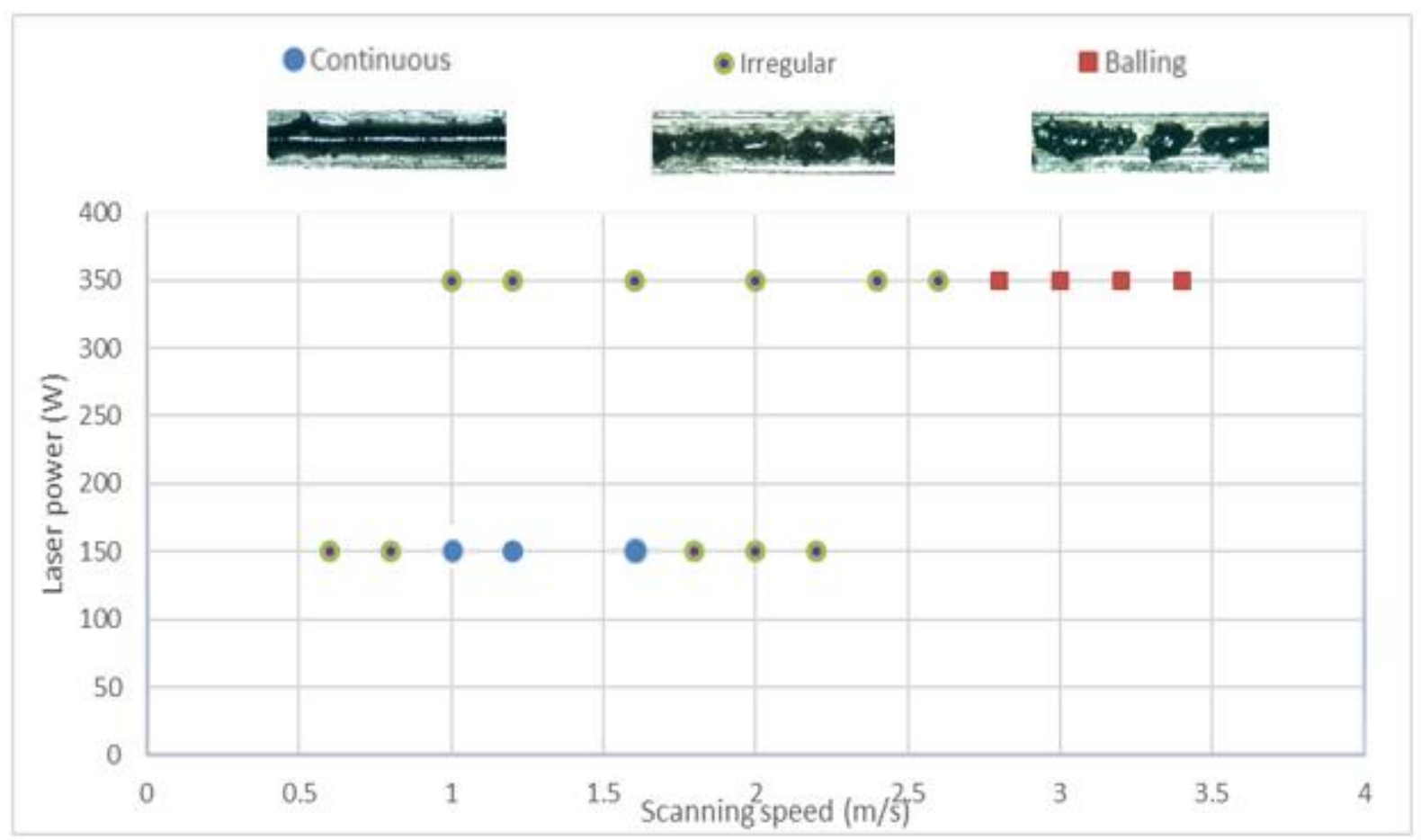

Figure 1. Top surface morphology of the Ti6Al single tracks produced at laser powers of $150 \mathrm{~W}$ and $350 \mathrm{~W}$ with corresponding scanning speeds ( 0.4 $-3.4 \mathrm{~m} / \mathrm{s})$

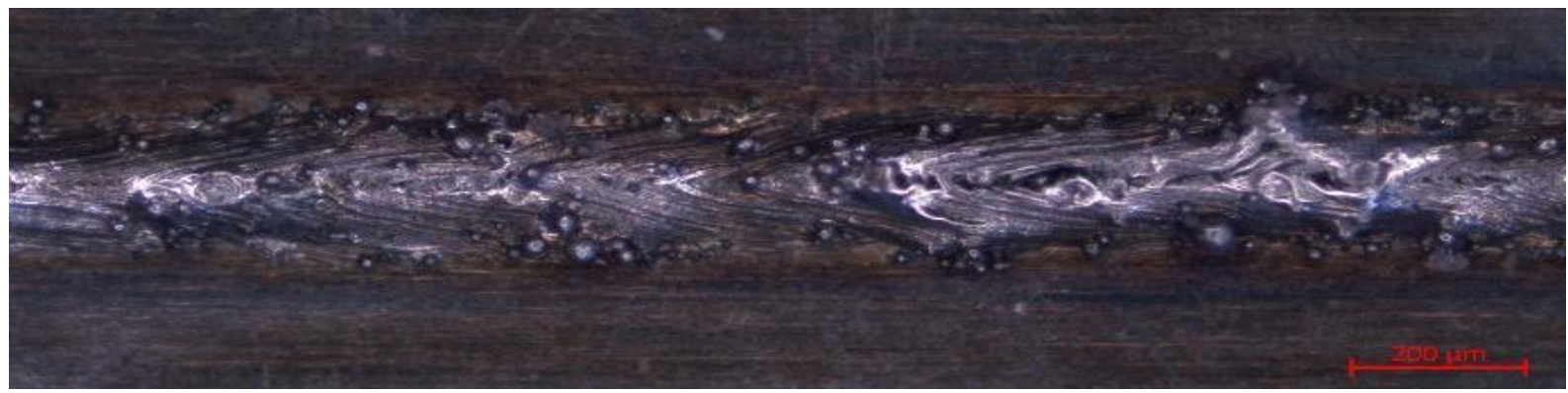

Figure 2. Satellites on $\mathrm{Ti} 6 \mathrm{Al}$ single tracks surface

There are satellites at the edge of the single tracks (Figure 2) as reported by previous authors $[9,17]$. Satellites are formed due to the incomplete melting of the powder particles in the peripheral zone of the laser spot. Since they are formed towards the end of the solidification process, there is insufficient transfer of the laser energy to melt them completely, as a result, they stick on to the surface of the tracks [17]. Satellites are generally considered as surface defects, which can have adverse effects on the mechanical properties of the final 3D objects [9].

The behaviour of the single tracks as a function of scanning speed was investigated and the results are shown in Figure 3. It was observed that at both laser powers of 150 $\mathrm{W}$ and $350 \mathrm{~W}$ the widths of the tracks reduced with increasing scanning speeds. Increasing the scanning speed reduces the laser energy transfer, which leads to a reduction in the temperature of the molten pool. The lower melting temperature would produce a limited molten flu id of high viscosity which would obstruct the free movement of the molten liquid hence reduction in the width of the single tracks. Conversely, a lower scanning speed leads to higher laser energy density and the resultant increase in temperature of the molten pool. The higher temperature within the molten pool would lead to a larger amount of liquid phase with low viscosity which would automatically enhance the easy flowing of the molten pool and the subsequent increase in the widths of the single tracks. Yadroitsava et al. [9] experimented with different powder layers of Ti6A14V and reported similar observations. Dzogbewu et al. [7] also focused on determining the optimum process parameter for Ti15Mo and noted a reduction of the track widths with increasing scanning speeds and increasing of the track widths with decreasing scanning speeds. 


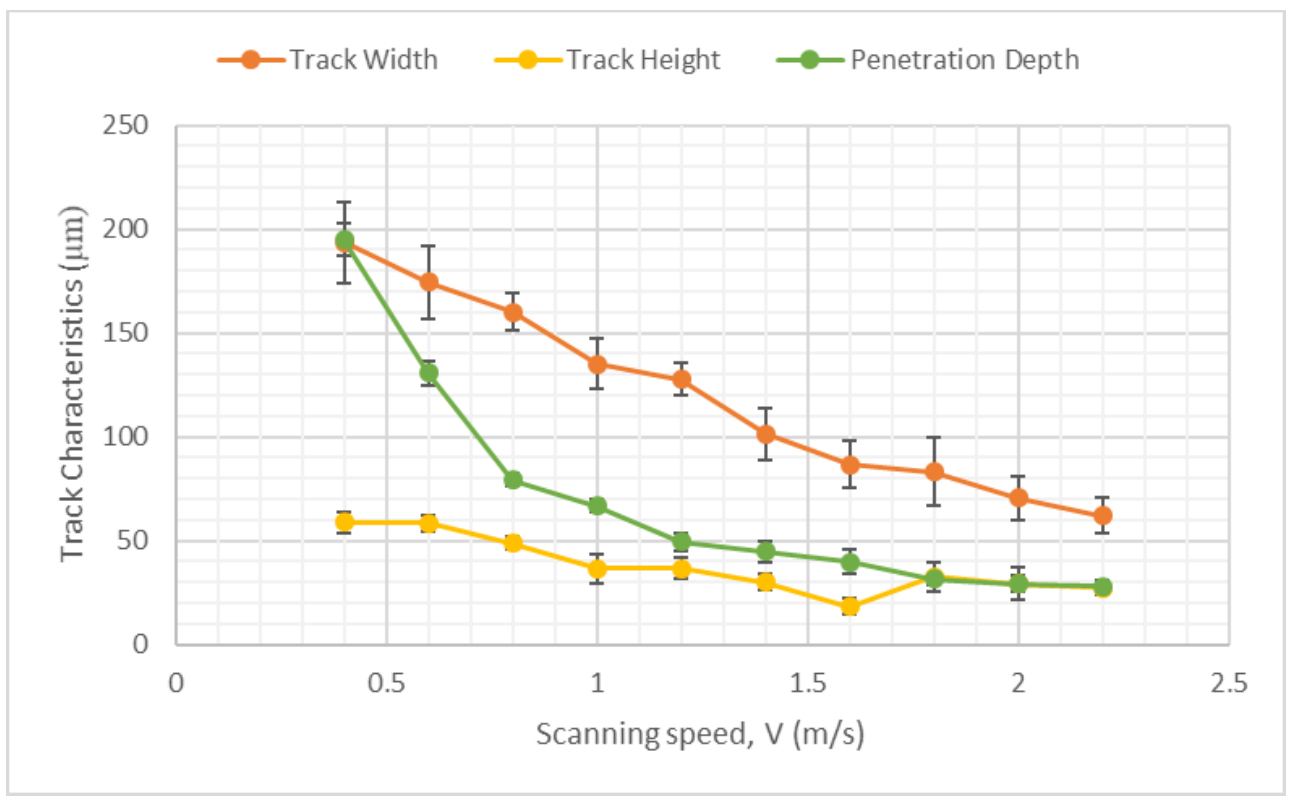

(A)

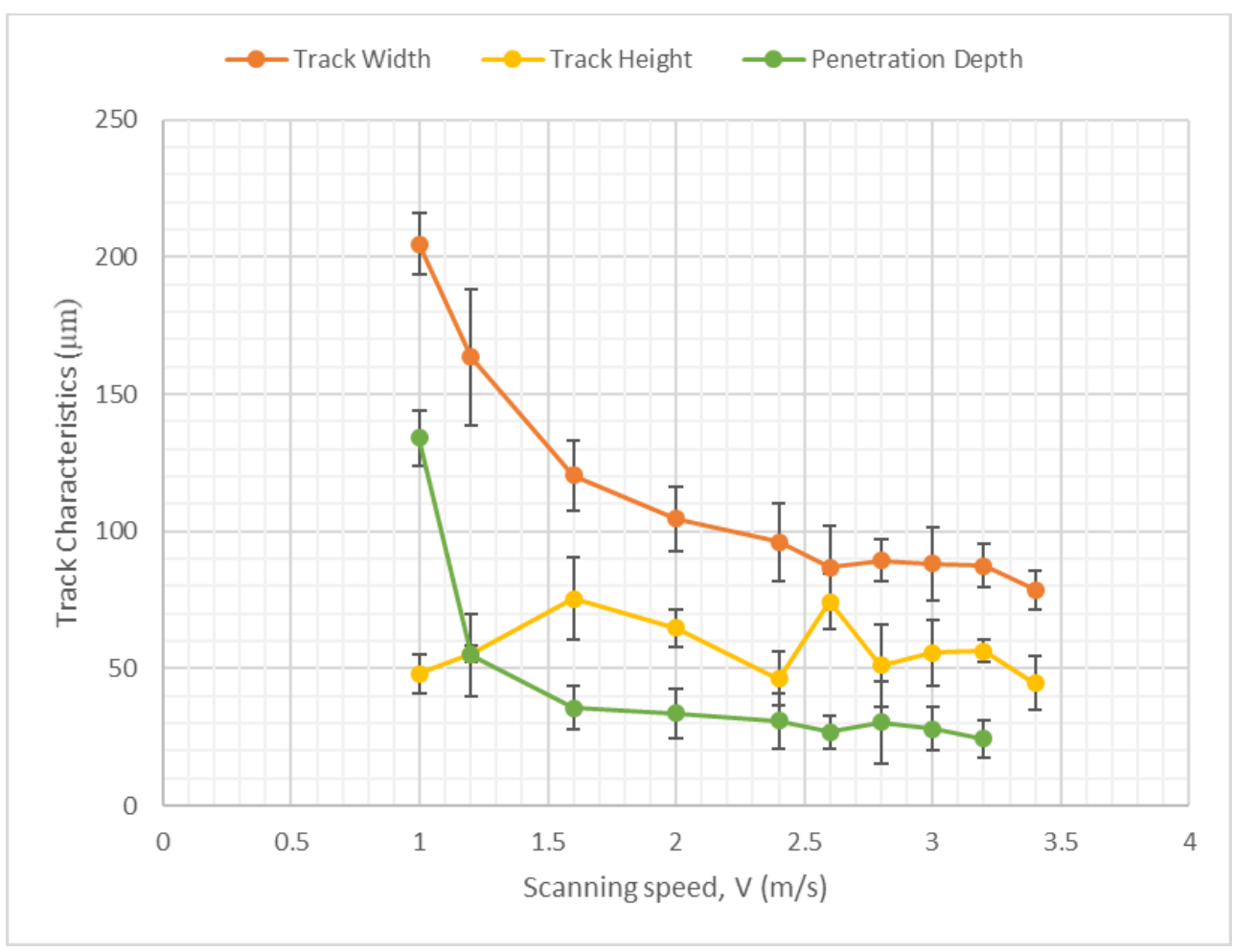

(B)

Figure 3. Track characteristics as a function of scanning speed at laser powers of (A) $150 \mathrm{~W}$, (B) $350 \mathrm{~W}$ 


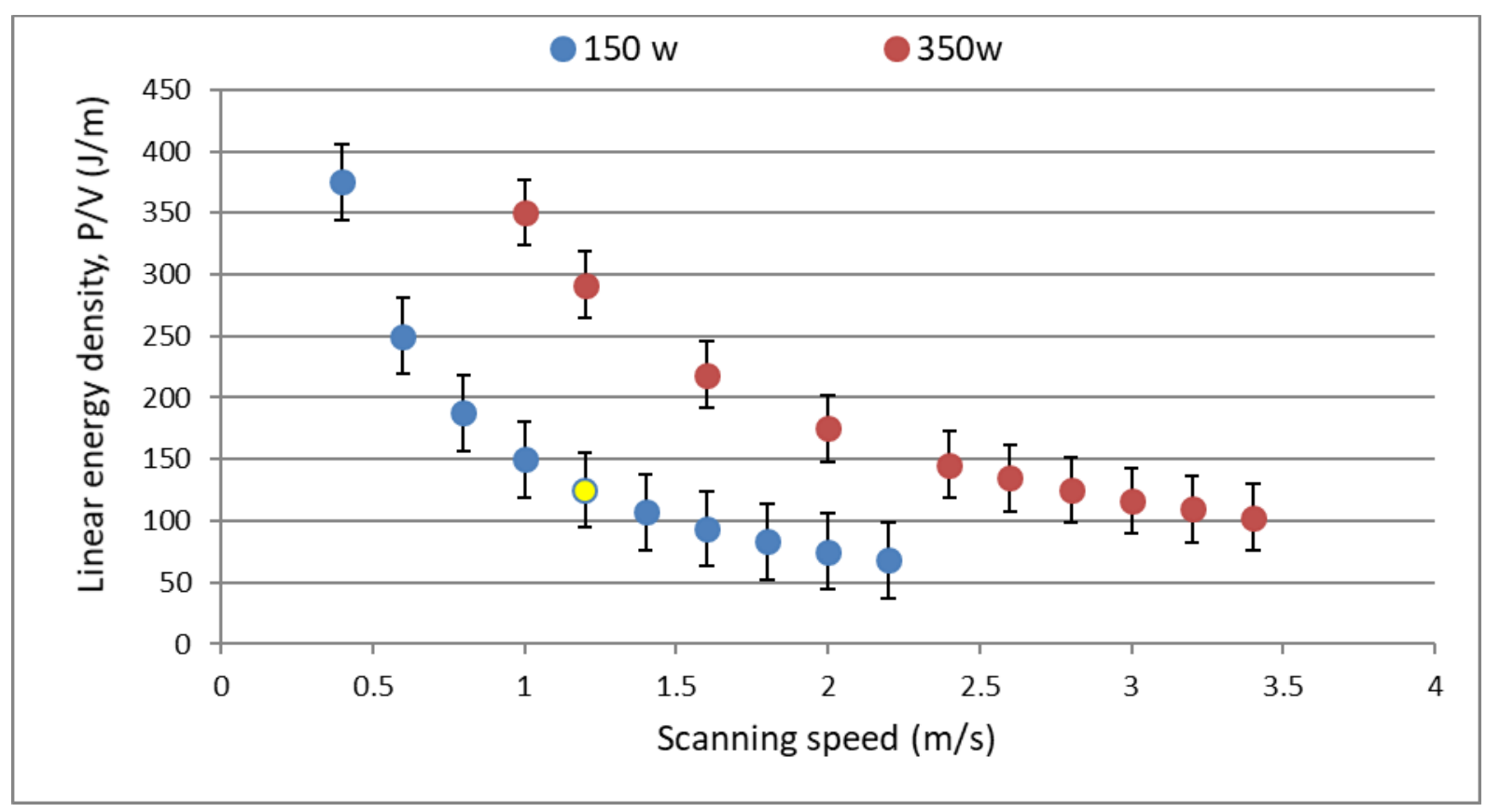

Figure 4. Linear energy density of Ti6Al single tracks at different scanning speeds and laser powers

Since the DMLS process is a layer-by-layer process, the cross sections of the single tracks were examined to determine the extent to which the laser energy density was able to melt the powder and penetrate into the substrate (previous layer). To ensure there is strong metallurgical 'welding' between the layers, the laser energy density must be enough to melt the powder and the substrate (previous layer). As depicted in Figure 4, the laser energy density decreases with increasing scanning speeds. Yadroitsev (2009) [18] noted that it is required that the laser energy is enough to re-melt the previous layer to ensure the stability of the molten pool.

During the DMLS process, three kinds of melting phenomenon can occur. The first phenomenon occurs when the laser energy density is not enough to melt the powder and penetrate the substrate, which is normally termed as poor penetration (Fig.5A). The second is when the laser energy is enough to melt the powder and penetrate the substrate to the desired depth, which is known as conduction mode (Fig.5B). The third melting condition is known as keyhole mode conduction (Fig.5C). A keyhole mode normally occurs when the combination of the selected process parameters leads to high laser energy absorption into the substrate and subsequent 'drilling' of the substrate. The drilling due to the absorption of the high laser energy contributes significantly to pore formation in the final DMLS products. Eagar and Tsai [18] and Yang et al. [17] noted that for a conduction mode, the morphology of the cross-section of the solidified molten pool should form a semi-circular ' $U$ ' shape (Fig.5B), while the morphology of the keyhole mode should resemble a ' $\mathrm{V}$ ' shape (Fig.5C). King et al. [16] also pointed out that the keyhole mode would occur if the penetration depth is greater than half the width of the track. Several authors have proposed theoretical and experimental models to predict the threshold that leads to the keyhole mode [19, 20].

For the current experiment, only the single track was produced at laser power $150 \mathrm{~W}$ and scanning speed of 1.2 $\mathrm{m} / \mathrm{s}$ morphology resembled a U shape which corresponds to the conduction mode (optimum process parameter Fig.5B). All the other process parameters did not meet the characteristics that defined optimum process parameters. At $150 \mathrm{~W}$ laser power with corres ponding scanning speeds from $1.4 \mathrm{~m} / \mathrm{s}-2.2 \mathrm{~m} / \mathrm{s}$ and at $350 \mathrm{~W}$ laser power with corresponding scanning speeds from $1.6 \mathrm{~m} / \mathrm{s}-3.4 \mathrm{~m} / \mathrm{s}$, poor penetration into the substrate was observed (Fig.5A). This is the effect of high scanning speeds, resulting in insufficient time for the laser beam to melt the powder completely and penetrate the substrate. The keyhole mode (Fig.5C) was observed at $150 \mathrm{~W}$ laser power and corresponding scanning speeds of $0.4 \mathrm{~m} / \mathrm{s}-1 \mathrm{~m} / \mathrm{s}$ and 350 $\mathrm{W}$ at scanning speeds from $1 \mathrm{~m} / \mathrm{s}-1.2 \mathrm{~m} / \mathrm{s}$. This could be attributed to the slow scanning speeds. At slow scanning speed, the laser beam radiation dwells at a particular spot for a re latively long time, which results in high laser energy absorption into the substrate. This resulted in the laser beam melting the powder and drilling very deep into the substrate forming the $\mathrm{V}$ shape keyhole mode profile (Fig.5C). As was observed in Fig. 3, the penetration depths of the single tracks decreased with increasing scanning speeds, since the time for the laser radiation at a particular spot reduced with increasing scanning speed. This observation concurs with the reports of previous authors [7, 15] 

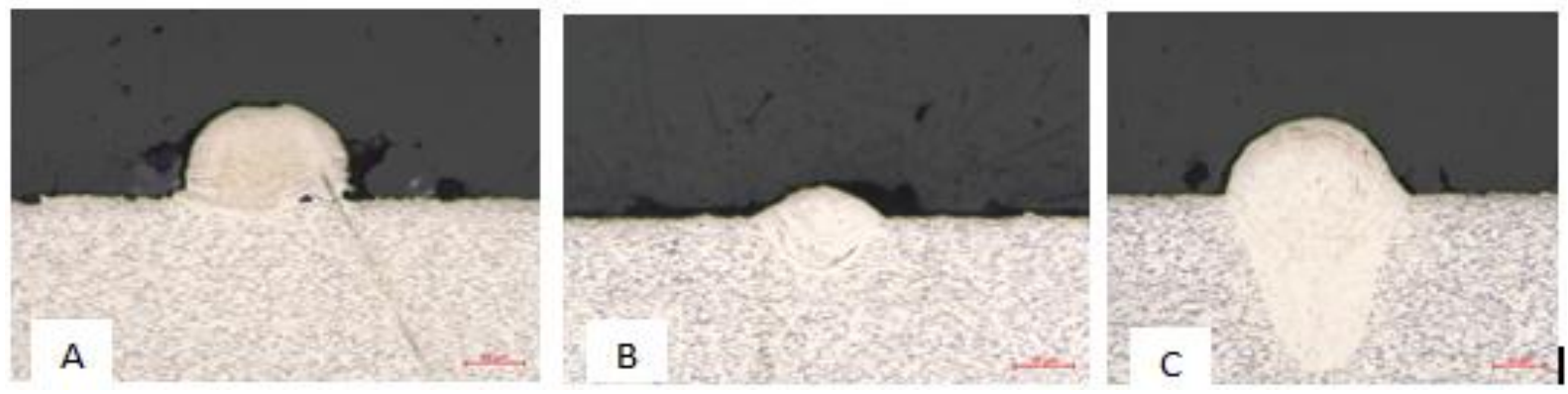

Figure 5. Penetration depth of the Ti6Al single tracks into the substrate

The height of the tracks was also investigated since it determined the surface morphology of the final 3D parts. Due to the single track side-by-side and subsequent layer-by-layer manufacturing method of the DMLS process, the nature of the track height affects the even deposition of the powder on the previous layer. A rough surface would lead to inhomogeneous powder deposition, which would trigger inconsistency in melt flow in the subsequent layers, resulting in a relatively rougher surface of the subsequent layer. Therefore, it is obligatory to optimize the melt flow to ensure the production of single tracks with suitable geometrical characteristics in order to produce a non-porous dense DMLS object.

However, the temperature distribution of the Gaussian laser beam that melts the metallic powder is not uniform [21], which leads to a non-uniform te mperature gradient of the molten pool. The un-even temperature in the molten pool provokes a surface tension gradient between the center and the edges of the molten pool, which induces ripple (un-even surface) formation as the molten metal solidifies [22, 23]. According to Körner et al. [24] and Körner et al. [25], the Gaussian laser beam melting process is very complex, and it is governed by laser beam absorption, Marangoni flow, viscosity, surface tension, capillary effects, gravity, etc., which leads to stochastic melt tracks with irregular, corrugated track heights. From Fig.3, it could be observed that the track heights were irregular at both laser powers and scanning speeds which concur with the observation of most previous authors [11, 17]. However, single tracks produced at laser power of 150 W (Fig.3A) demonstrated a relatively less irregular behavior than single tracks produced at $350 \mathrm{~W}$ (Fig.3B). It could be inferred from this observation that within an optimum process parameter window the heights of the single tracks are less irregular, hence tracks produced at optimum process parameters would demonstrate less irregular track heights, which implies that samples that are produced at optimum process parameters would demonstrate relatively s mooth surfaces. Yang et al. [17] produced Ti6Al4V single tracks at 100-400 W laser powers and reported a nearly uniform track height. The authors explained that the uniform track heights were due to the low $(20-40 \mu \mathrm{m})$ powder layer thickness.

\subsection{Single Layers}

Based on the hierarchical design principles proposed by Yadroitsev et al. [9] for determining optimum process parameters for the DMLS process, single layers were produced (Fig.6) at laser power of $150 \mathrm{~W}$ with the corresponding scanning speed of $1.2 \mathrm{~m} / \mathrm{s}$ to determine the optimu $m$ hatch distance and the homogeneity of the Al in the Ti alloy matrix. Two scanning strategies (single scan and re-scan) were employed to produce the single layers at three different hatch distances $(80 \mu \mathrm{m}, 90 \mu \mathrm{m}$ and $100 \mu \mathrm{m})$. The optical and scanning electron microscope investigations revealed that the powders melted completely to form ho mogeneous layers of the alloy (Fig.6). There was complete overlapping of the single tracks to form dense single layers which were metallurgically fused onto the substrate. Satellites were observed on the surfaces of the single layers after the single scan. These satellites were removed after the rescanning process. The surface roughness of the samples after the single scan was recorded as $10 \pm 1.2$ for the $\mathrm{Rz}$, and after the rescanning it reduced to $6 \pm 0.9$. The different hatch distances did not have any significant effects on the distribution of the Al in the $\mathrm{T} i$ alloy matrix and the surface roughness of the single layers. All the samples demonstrated similar surface morphology at all three different hatch distances. 


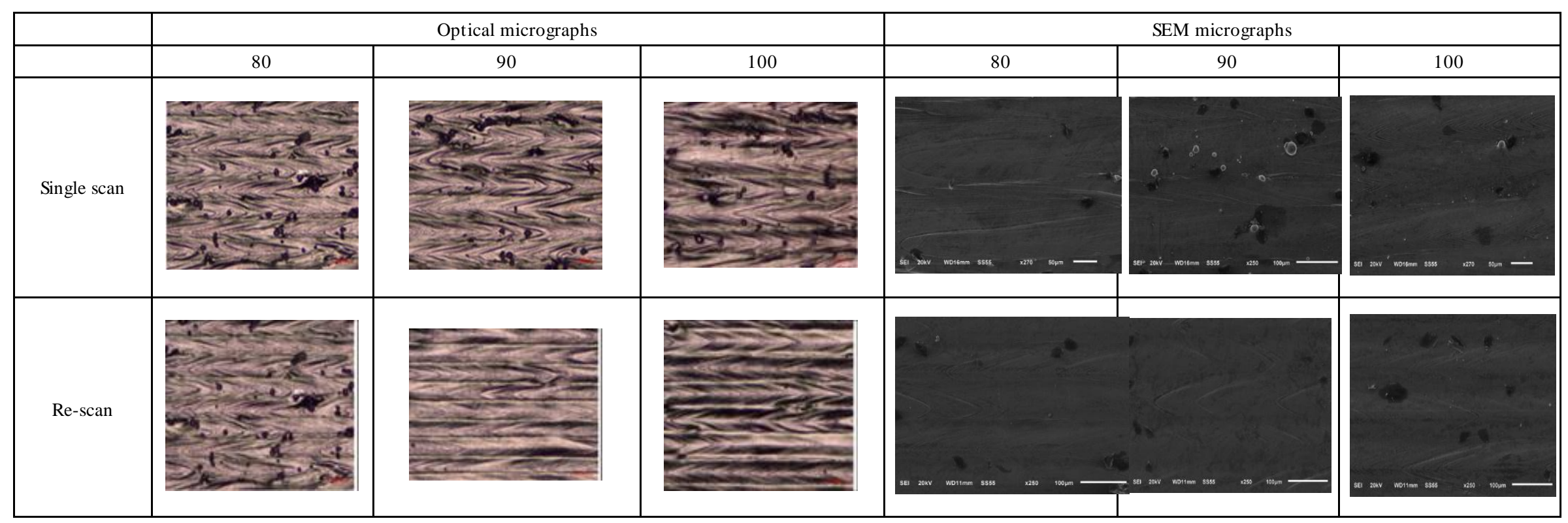

(A)

(B)

Figure 6. Top surfaces of Ti6Al single layers built at $150 \mathrm{~W}$ and $1.2 \mathrm{~m} / \mathrm{s}$ at hatch distances of $80 \mu \mathrm{m}, 90 \mu \mathrm{m}$ and $100 \mu \mathrm{m}$. (A) Optical mic rographs (B) SEM micrographs 


\subsubsection{Object Analysis}

To ensure a high degree of overlapping, cubes were produced (Fig.7A) at hatch distance of $80 \mu \mathrm{m}$ to investigate the properties obtained by using the optimum process parameters $(150 \mathrm{~W}, 1.2 \mathrm{~m} / \mathrm{s}$ and $80 \mu \mathrm{m})$ to build a 3D object. Using the optical microscope, it was noted that the powder melted completely and there were no visible satellites at the top, side and front planes (Fig.8). The front (y-z plane) and the side ( $\mathrm{x}-\mathrm{z}$ plane) view microstructures showed overlapping of subsequent scanned tracks due to the optimu $m$ hatch distance. The overlapping edges of the single tracks were curved and were noted on the front and the side views. These curves signify the merging of each layer into the nearby layers (Fig.8B \& C).

From Fig. $8 \mathrm{~A}, \alpha+\beta$ microstructure is observed, with the primary $\alpha$ grains in the transformed $\beta$ matrix. In Fig. $8 \mathrm{~B}$ and $8 \mathrm{C}$, needles of fine acicular martensite was found inside the prior $\beta$ grains of the Ti alloy, which signifies the high cooling rate that characterizes the DMLS process [26]. It was reported that the heating and cooling process that occurs simultaneously in the build chamber during the DMLS process occurs at $\left(\sim 10^{4}-10^{6}{ }^{\circ} \mathrm{C} / s\right)[27,28]$. It is this rapid heating and cooling that lead to the formation of the martensitic microstructure of DMLS built parts. The martensitic microstructure which limits the ductility of a DMLS built part can be overcome by post-thermal treatment process [29]. It is also worth mentioning that a section of the materials science research commun ity are of the view that the high rate of heating and cooling reported during the DMLS process is quite ambiguous and still a matter of research [30].
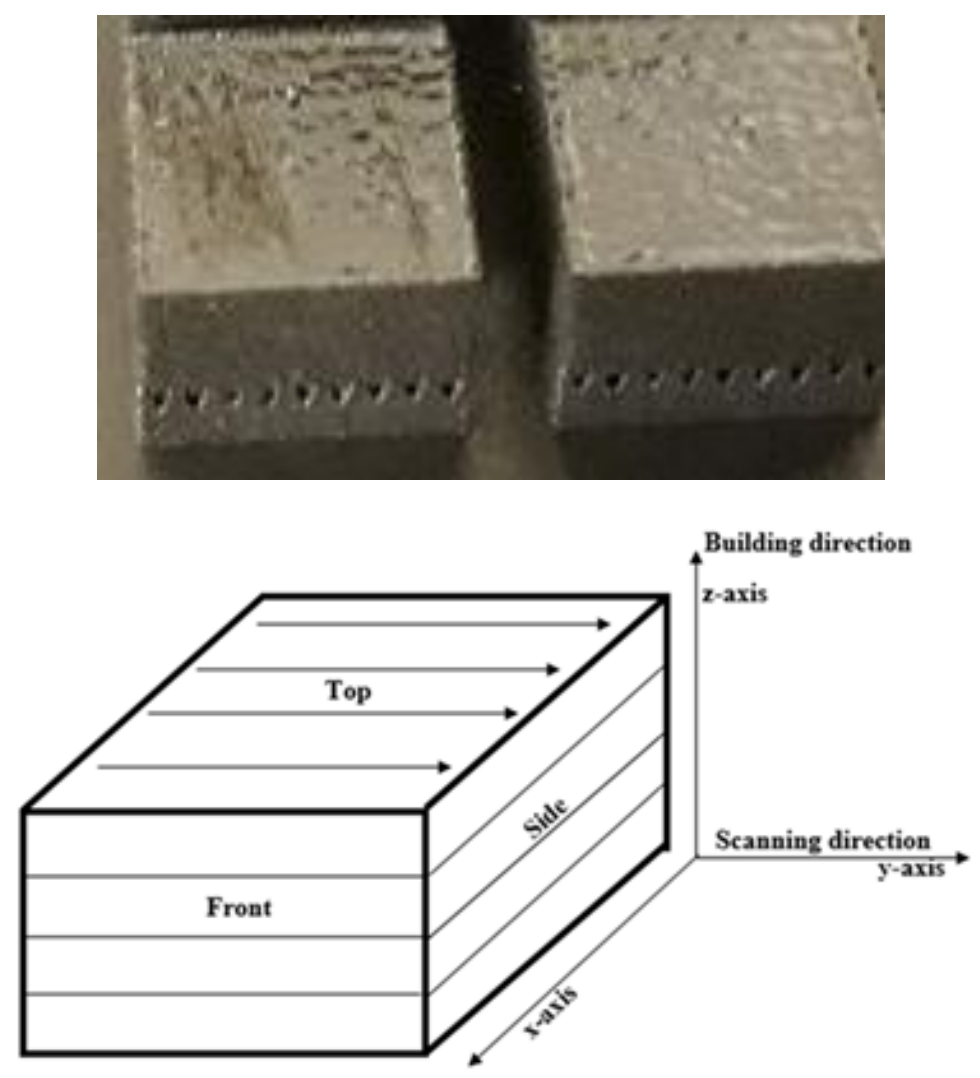

Figure 7. Cubes of $\mathrm{Ti} 6 \mathrm{Al}(\mathrm{A})$ and laser scanning coordination system (B)
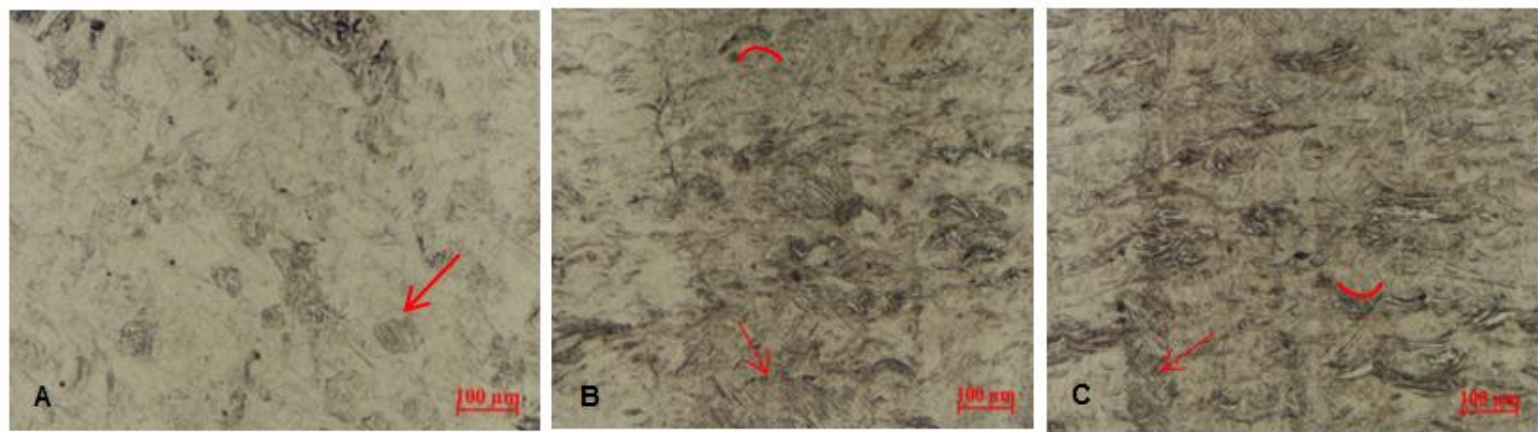

Figure 8. Microstructure of Ti6Al 3D part. (a) Top view (b) Side view (c) Front view 


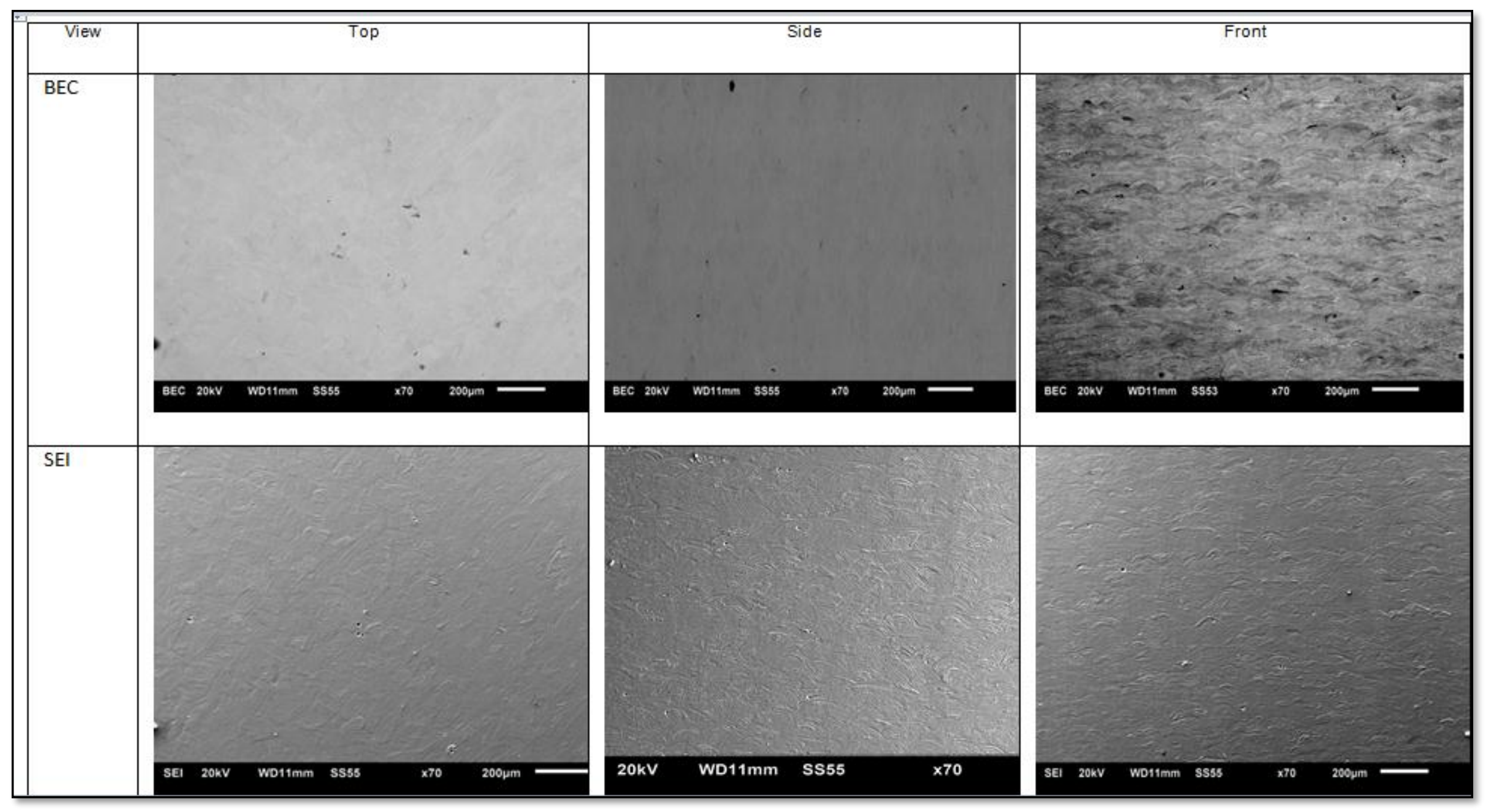

Figure 9. BEC and SEI SEM micrographs of the sections of the Ti6Al cube 
Backscattered electron (BEC) and secondary electron (SEI) images of the three views (top, side and front) reveal dark spots on the micrographs (Fig.9). These spots are possible pores in the $3 \mathrm{D}$ part. These pores are found in the (x-y plane) in-between the solidified layers. Porosity in-between solidified layers are known as interlayer porosity and can be caused by non-uniform powder delivery. During the layer-by-layer building process of DMLS, if the surface of the previously solidified layer is uneven, then the next powder distribution would be uneven and interlayer pores can form. The non-uniform track height (Fig.3) can lead to such occurrences during the DMLS melting process.

Further analys is was conducted to confirm the presence of the micropores in the DMLS built part. The samples were re-polished and optical micrographs (Fig.10) were taken since the optical microscope gives a clear contrast view of such defects. From the optical micrographs (Fig. 10) it was confirmed that micropores were present in the DMLS 3D built part. The pores were less than $20 \mu \mathrm{m}$ when measured on mic rographs of all three cross -sectional views, hence the samples we re considered as well-built dense 3D objects as reported elsewhere [31]. It was empirically proven and generally accepted that DMLS samples with pores size less than $20 \mu \mathrm{m}$ would demonstrate stable mechanical properties for engineering applications and are therefore considered as dense well-built 3D objects [8].

EDS elemental mapping analyses were done for the three views of the 3D part (Fig.11). The Al distribution in the Ti matrix was even and homogeneous. The elemental mapping (Fig.11) and the microstructure in Fig.8 clearly demonstrate that the DMLS process was able to produce a homogeneous alloy of Ti6Al.

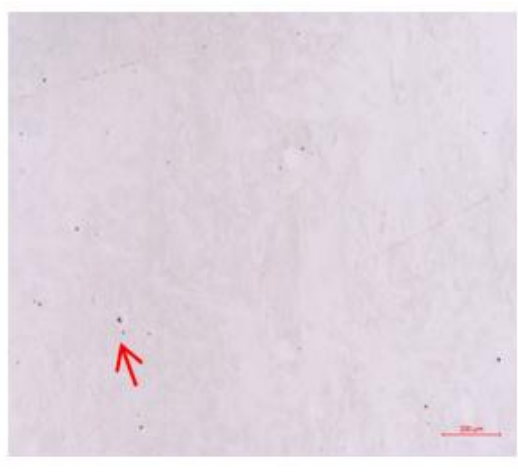

(A)

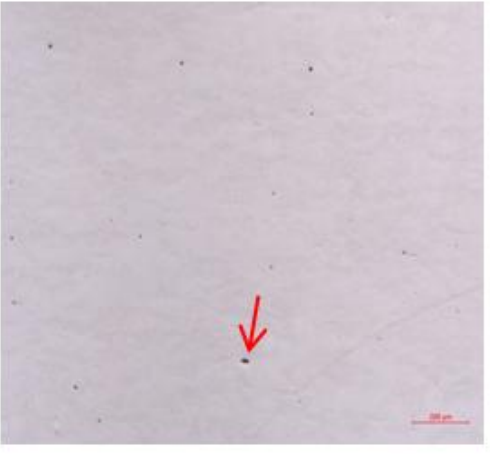

(B)

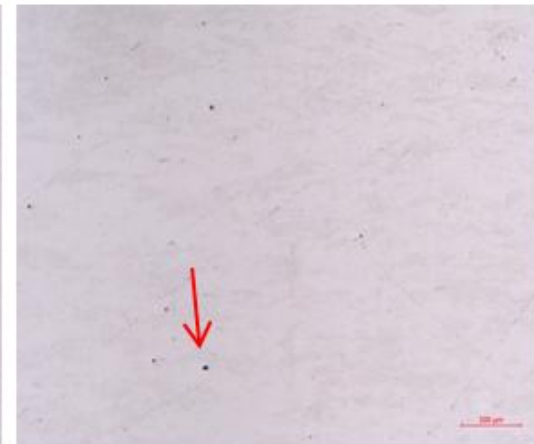

(C)

Figure 10. Optical micrographs of Ti6Al 3D part. (A) Top view (B) Side view (C) Front view un -etched

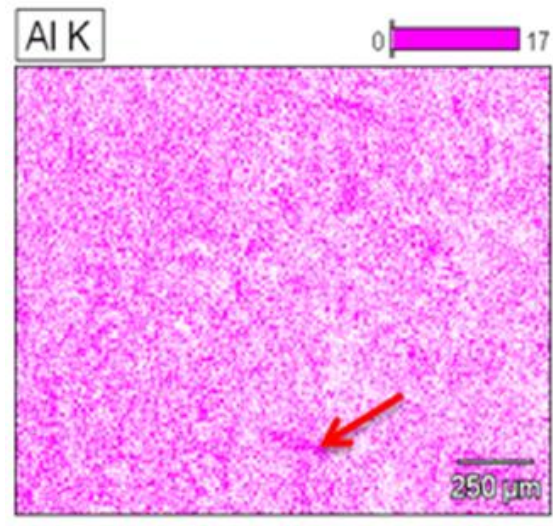

(a)

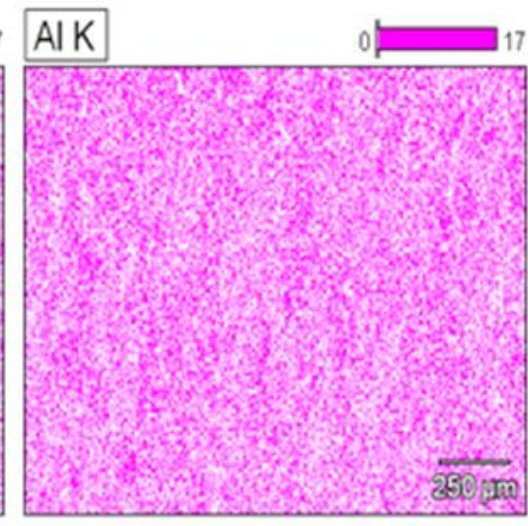

(b)

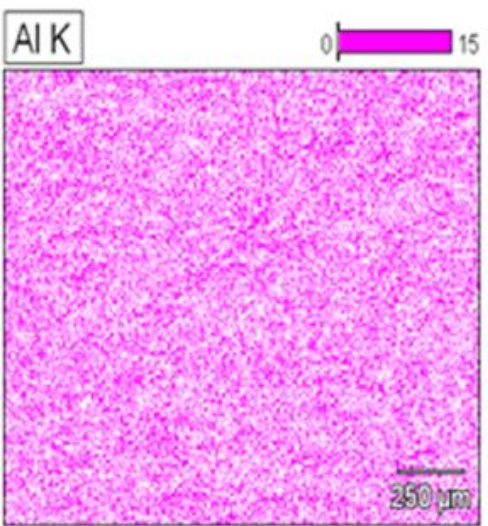

(c)

Figure 11. EDS Al elemental mapping of TI6Al 3D part. (a) Top view (b) Side view (c) Front view 
The EDS investigation revealed an average of $4 \% \mathrm{Al}$ in the Ti matrix of the 3D part, which implies that $2 \%$ of the Al was lost during the DMLS process. This phenomenon of Al loss could be attributed to the thermophysical differences between the two materials as given in Table 1.

Table 1. Thermal and physical properties of $\mathrm{Ti}$ and $\mathrm{Al}[32,33]$

\begin{tabular}{|l|l|l|}
\hline Properties & $\mathrm{Ti}$ & $\mathrm{Al}$ \\
\hline Thermal conductivity & $17 \mathrm{~W} /(\mathrm{m} . \mathrm{K})$ & $205 \mathrm{~W} /(\mathrm{m} . \mathrm{K})$ \\
\hline Specific heat capacity & $528 \mathrm{~J} /(\mathrm{kg} . \mathrm{K})$ & $900 \mathrm{~J} /(\mathrm{kg} \cdot \mathrm{K})$ \\
\hline Melting point & $1668^{\circ} \mathrm{C}$ & $660^{\circ} \mathrm{C}$ \\
\hline Density & $4500 \mathrm{~kg} / \mathrm{m}^{3}$ & $2710 \mathrm{~kg} / \mathrm{m}^{3}$ \\
\hline
\end{tabular}

As indicated in Table 1, Al has a higher specific heat capacity and a higher thermal conductivity than $\mathrm{Ti}$, which results in $\mathrm{Al}$ absorbing more laser radiation than $\mathrm{Ti}$. The high absorptive capacity of Al means it tends to melt faster than Ti. Secondly, the melting point of $\mathrm{Al}\left(660^{\circ} \mathrm{C}\right)$ is lower than $\mathrm{Ti}\left(1668^{\circ} \mathrm{C}\right)$, hence it will absorb the laser radiation faster and melt at a lower temperature than Ti. As result, $\mathrm{Al}$ could evaporate in the process which explains the $2 \%$ reduction of $\mathrm{Al}$ in the bulk material. The lower density of Al $\left(2710 \mathrm{~kg} / \mathrm{m}^{3}\right)$ when co mpared to Ti $\left(4500 \mathrm{~kg} / \mathrm{m}^{3}\right)$ could also have contributed to the loss of Al. Since the density of $\mathrm{Al}$ is only $60 \%$ that of $\mathrm{Ti}, \mathrm{Al}$ would be in relatively higher concentration towards the top of the melt pool than at the bottom, which could have increased the Al evaporation rate.

The Ti-Al phase diagram in Fig. 12 is used to determined which phase is expected at equilibrium for $6 \mathrm{wt} \% \mathrm{Al}$ content of $\mathrm{Ti}$ at te mperature in ${ }^{\circ} \mathrm{C}$. Two stable equilibrium states are possible at $6 \mathrm{wt} \%$ Al content, namely hexagonal close-packed (hcp) $\alpha$-Ti which is stable from room temperature up to $882{ }^{\circ} \mathrm{C}$ and body-centered cubic (bcc) $\beta$-Ti which is stable from $882{ }^{0} \mathrm{C}$ up to the melting temperature [34]. The Al will form a complete substitutional solid solution in the Ti matrix [35].

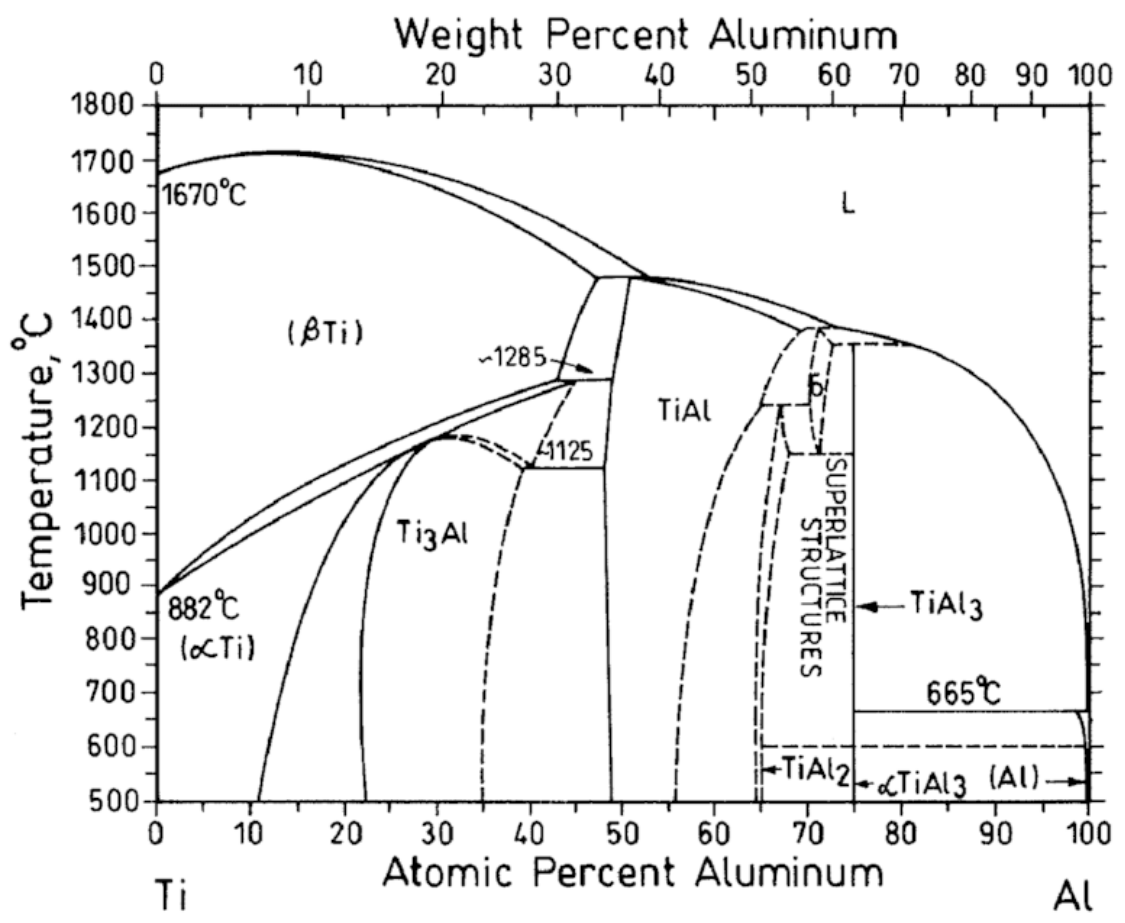

Figure 12. Ti-Al phase diagram [34] 


\section{Conclusions}

The successful production of homogeneous, non-porous dense 3D objects (cubes) with the optimum process parameters demonstrated that the DMLS method of manufacturing is capable of producing the Ti6Al alloy with the desired microstructural properties for high temperature applications. Using the DMLS process would permit the manufacturing Ti6Al components with complex geometrical configurations as required in the aircraft and the automotive industries. The net shapes would enhance the cost-effectiveness of the manufacturing process. The reduced weight of the near net shape Ti6Al DMLS built parts could enhance the energy efficiency of turbines constructed with such parts for high temperature applications.

\section{Acknowledgements}

This work is based on research supported by the Collaborative Program in Additive Manufacturing (Contract № CSIR-NLC-CPAM-18-MOA-CUT-01).

\section{REFERENCES}

[1] W. Chen and Z. Li, "Additive manufacturing of titanium aluminides," In Additive Manufacturing for the Aerospace Industry, pp. 235-263, 2019.

[2] D. Vojtěch, B. Bártová and T. Kubatík, "High temperature oxidation of titanium-silicon alloys," Materials Science and Engineering: A, vol. 361, no. 1, pp. 50-57, 2003.

[3] S. A. Raji, A. P. I. Popoola, S. L. Pity ana, O. M. Popoola and F. Aramide, " Laser Based Additive Manufacturing Technology for Fabrication of Titanium Aluminide-Based Composites in Aerospace Component Applications," In Environmental Impact of Aviation and Sustainable Solutions. IntechOpen., 2019.

[4] W. E. Voice, M. Henderson, E. F. Shelton and X. Wu "Gamma titanium aluminide, TNB," Intermetallics, vol. 13, no. 9, pp. 959-964, 2005.

[5] A. Zenani, W. Du Preez, T. C. Dzogbewu and I. Yadroitsev, "Metal Additive Manufacturing of Ti6Al from Blended Elemental Powders, International Conference on Competitive Manufacturing (COMA '19) Proceedings, Stellenbosch, South Africa, pp 181-187, 2019.

[6] M. Thomas, T. Malot, P. Aubry, C. Colin, T. Vilaro and P. Bertrand, "The prospects for additive manufacturing of bulk TiAl alloy," Materials at High Temperatures, vol. 33, no. 4, pp. 571-577, 2016

[7] T. C. Dzogbewu, I. Yadroitsev, P. Krakhmalev, I. Yadroitsava and A. Du Plessis, "Optimal process parameters for in-situ alloyed Ti15Mo structures by Direct Metal Laser Sintering," The Twenty-Eighth Annual International Solid Freeform Fabrication (SFF)
Symposium - An Additive Manufacturing Conference, The University of Texas, Austin, 2017.

[8] T. C. Dzogbewu, "Direct metal laser sintering of titanium alloys for biomedical applications," (Doctoral dissertation), Central University of Technology, Free State, Bloemfontein, South Africa, 2017.

[9] I. Yadroitsev, P. Krakhmalev and I. Yadroitsava, "Hierarchical design principles of selective laser melting for high quality metallic objects," Additive Manufacturing, vol. 7, pp. 45-56, 2015

[10] B. P. Bewlay, M. Weimer, T. Kelly, A. Suzuki and P. R. Subramanian, "The science, technology, and implementation of TiAl alloys in commercial aircraft engines," 2013.

[11] T. C. Dzogbewu, "Evaluation of Ti15Mo alloy manufactured by DMLS from elemental powders," RAPDASA 2017 Conference Proceedings, pp. 75 - 84, Durban, South Africa, 2017.

[12] I. Yadroitsev, A. Gusarov, I. Yadroitsava and I. Smurov, "Single track formation in selective laser melting of metal powders," Journal of Materials Processing Technology, vol. 210, no. 12, pp. 1624-1631, 2010.

[13] I. Yadroitsev, Selective laser melting: direct manufacturing of 3D-objects by selective laser melting of metal powders, Saarbrucken: LAP Lambert Academic Publishing AG \& Co. KG., 2009.

[14] I. Yadroitsev, P. Krakhmalev, I. Yadroitsava, S. Johansson and I. Smurov, "Energy input effect on morphology and microstructure of selective laser melting single track from metallic powder," Journal of Materials Processing Technology, vol. 213, no. 4, pp.606-613, 2013.

[15] S. A. Khairallah, A. Anderson, A. Rubenchik and W. E. King, "Laser powder-bed fusion additive manufacturing: Physics of complex melt flow and formation mechanisms of pores, spatter, and denudation zones," Acta Materialia, vol. 108, pp. 36-45, 2016.

[16] W. E. King, H. D. Barth, V. M. Castillo, G. F. Gallegos, J. W. Gibbs, D. E. Hahn, C. Kamath and A. M. Rubenchik, "Observation of keyhole-mode laser melting in laser powder-bed fusion additive manufacturing," Journal of Materials Processing Technology, vol. 214, no. 12, pp. 2915-2925, 2014.

[17] J. Yang, J. Han, H. Yu, J. Yin, M. Gao, Z. Wang and X. Zeng, "Role of molten pool mode on formability, microstructure and mechanical properties of selective laser melted Ti-6Al-4V alloy," Materials \& Design, vol. 110, pp. 558-570, 2016

[18] T. W. Eagar and N. S. Tsai, "Temperature fields produced by traveling distributed heat sources," Welding Journal, vol 62, no. 12 , pp. 346-355, 1983.

[19] D. B. Hann, J. Iammi and J. Folkes, "A simple methodology for predicting laser-weld properties from material and laser parameters," Journal of Physics D: Applied Physics, vol. 44, no. 44 , p. 445401, 2011

[20] A. Klassen and K. Carolin, "Modelling of electron beam absorption in complex geometries," Journal of Physics D: Applied Physics, vol. 47, no. 6, p.065307, 2014. 
[21] C. L. Chan, J. Mazumder and M. M. Chen, "Three-dimensional axisymmetric model for convection in laser-melted pools," Materials Science and Technology, vol. 3, no. 4, pp. 306-311, 1987.

[22] S. Kou, C. Limmaneevichitr and P. S. Wei, "Oscillatory Marangoni flow: a fundamental study by conduction-mode laser spot welding," Welding Journal, vol. 90, no. 12, pp. 229-240, 2011.

[23] C. Qiu, C. Panwisawas, M. Ward, H. C. Basoalto, J. W. Brooks and M.M. Attallah, "On the role of melt flow in to the surface structure and porosity development during selective laser melting," Acta Materialia, vol. 96, pp. 72-79, 2015.

[24] C. Körner, E. Attar and P. Heinl, "Mesoscopic simulation of selective beam melting processes," Journal of Materials Processing Technology, vol. 211, no. 6, pp.978-98, 2011.

[25] C. Körner, A. Bauereiß and E. Attar, "Fundamental consolidation mech anisms during selective beam melting of powders," Modelling and Simulation in Materials Science and Engineering, vol. 21, no. 8, p. 085011, 2013.

[26] L. Thijs, F. Verhaeghe, T. Craeghs, J. Van Humbeeck and J. P. Kruth, "A study of the microstructural evolution during selective laser melting of Ti-6Al-4V," Acta Materialia, vol. 58, no. 9, pp. 3303-3312, 2010.

[27] E. Brandl and D. Greitemeier, "Microstructure of additive layer manufactured $\mathrm{Ti}-6 \mathrm{Al}-4 \mathrm{~V}$ after exceptional post heat treatments," Materials Letters, vol. 81, pp. 84-87, 2012.

[28] I. A. Roberts, C. J. Wang, R. Esterlein, M. Stanford and D. J. Mynors, "A three-dimensional finite element analy sis of the temperature field during laser melting of metal powders in additive layer manufacturing," International Journal of Machine Tools and Manufacture, vol. 49, no. 12, pp. 916-923, 2009.

[29] T. Becker, M. van Rooyen and D. Dimitrov, "Heat treatment of Ti-6Al-4V produced by lasercusing," South African Journal of Industrial Engineering, vol. 26, no. 2, pp.93-103, 2015.

[30] M. Yan and P. Yu, "An Overview of Densification, Microstructure and Mechanical Property of Additively Manufactured Ti-6Al-4V-Comparison among Selective Laser Melting, Electron Beam Melting, Laser Metal Deposition and Selective Laser Sintering, and with Conventional Powder," In Sintering Techniques of Materials. InTech., 2015.

[31] T. C. Dzogbewu, L. Monaheng, J. Els, I. van Zyl, W. B. du Preez, I. Yadroitsava and I. Yadroitsev, "Evaluation of the Compressive Mechanical Properties of Cellular DMLS Structures for Biomedical Applications," 17th RAPDASA Annual International Conference, Vanderbijlpark, South Africa, 2016.

[32] AZO, "AZO materials," 2015. [Online]. Available: http://www.azom.com. [Accessed 12 February 2020].

[33] MatWeb, "Material property data," 2016. [Online]. Available: http://www.matweb.com. [Accessed 12 February 2020].

[34] H. Baker, "Introduction to alloy phase diagrams". Materials Park, OH: ASM International, 1992.
[35] H. Sibum, V. Güther, O. Roidl, F. Habashi, H. Uwe Wolf, H. and C. Siemers, "Titanium, titanium alloys, and titanium compounds", Ullmann's encyclopedia of industrial chemistry, pp.1-35, 2000. 